\title{
Mammary serum amyloid A3 activates involution of the mammary gland in dairy cows
}

\author{
A. Domènech, ${ }^{*}$ S. Parés, ${ }^{*}$ A. Bach, ${ }^{*} \dagger$ and A. Arís ${ }^{* 1}$ \\ *Department of Ruminant Production, IRTA, Institute of Research in Agriculture and Technology. Torre Marimon, km 12,1 C-59, \\ Caldes de Montbui, 08140, Barcelona, Spain \\ †ICREA, Institució Catalana de Recerca i Estudis Avançats, 08007, Barcelona, Spain
}

\section{ABSTRACT}

The dry period is a nonlactating phase in which senescent mammary cells are regenerated, which is thought to optimize milk production in the subsequent lactation. In bovines, the dry period normally coexists with pregnancy and the lactogenic hormones delay mammary gland involution and impair the activation of immune system to fight the risk of intramammary infections. Conventionally, long dry periods of up to 60 $\mathrm{d}$ are required to allow sufficient mammary regeneration for full milk yield in the next lactation. The aim of this study was to evaluate the potential of mammary serum amyloid A3 (M-SAA3) as an activator of the involution of the mammary gland. One milligram of recombinant M-SAA3 and the corresponding negative controls (saline solution and lipopolysaccharide) were infused into the mammary gland via the teat canal, and mammary secretion samples were taken during the first $3 \mathrm{~d}$ after drying off to analyze metalloproteinase activity, somatic cell count, protein, and fat contents. Primary mammary gland epithelial cell cultures and bovine dendritic cells, obtained from necropsy tissue and blood, respectively, were incubated with and without M-SAA3 and cytokine expression was quantified. Last, the protective role of the M-SAA3 against infections was evaluated after a Staphylococcus aureus challenge. Matrix metalloproteinase 9 activity, a key protein that directly participates in the onset of the involution process, was greater in quarters treated with the M-SAA3. Protein content was increased in mammary secretions compared with control quarters. M-SAA3 increased cytokines directly related to innate immunity in both epithelial and dendritic cells and reduced the infection by Staphylococcus aureus.

Key words: dry cow period, innate immunity, mammary serum amyloid A3, Staphylococcus aureus

Received May 26, 2014.

Accepted September 4, 2014.

${ }^{1}$ Corresponding author: anna.aris@irta.cat

\section{INTRODUCTION}

Milk production usually peaks before conception and remains high while the cow is pregnant for around $70 \%$ of the lactation period (Capuco and Akers, 1999). A dry period between lactations is necessary to renew senescent epithelial cells of the mammary gland and ensure optimal milk production in the next lactation (Capuco et al., 1997). Involution of the mammary gland in pregnant cows is slower than in other species where it does not normally coexist with pregnancy (Capuco and Akers, 1999; Pezeshki et al., 2010). This requires long dry periods up to $60 \mathrm{~d}$, which significantly reduce productivity (Noble and Hurley, 1999; Pezeshki et al., 2010).

The dry period is typified by 2 main phases of cell turnover: mammary gland involution characterized by acute apoptosis, and cell regeneration before the next lactation (De Vries et al., 2010). A peak of apoptosis is observed during the first $72 \mathrm{~h}$ after milk cessation, continuing along the rest of the dry period and combined with an increase in cell proliferation (Annen et al., 2004). Physiologically, milk stasis is initiated by stopping milk removal from the mammary gland and promoted by a decrease in lactogenic protein and hormonal factors that induce an active mammary gland involution and in turn stimulate contraction of the parenchyma and cessation of milk secretion (Wilde et al., 1999; Accorsi et al., 2002; Pezeshki et al., 2010).

The mammary gland is composed of secretory epithelial cells and stromal tissue components with different proportions of cell types (Muschler et al., 2010). Both tissues are separated by the extracellular matrix (ECM), which influences the development and biology of the mammary gland (Lin and Bissell, 1993; Streuli, 2003). The ECM directly establishes and maintains the mammary gland differentiated state and regulates apoptosis (Talhouk et al., 1992; Bodreau et al., 1995). The proteolytic destruction of the ECM induces widespread apoptosis and involution of the mammary gland (Bodreau et al., 1995). Several proteases are involved in the ECM degradation, but basically the matrix 
metalloproteinases (MMP) are the key enzymes of this process (Rabot et al., 2007). Moreover, other functions have been assigned to MMP such as the release of growth factors and cytokines, which modulate other key aspects of the dry period such as the activation of the immune system and cell growth (Rabot et al., 2007).

In the early dry period, there is an increased risk of intramammary infections. Milk stasis increases pressure within the mammary gland, promoting milk leakage and susceptibility to bacterial infection (Burvenich et al., 2007). It has been proposed that animals with high milk yields are more susceptible to contracting intramammary infections because they have a delayed formation of the keratin plug, impairing the occlusion of the teat canal. The intramammary infections contracted during the dry period have been associated with increased infection prevalence in the next lactation, which causes loss of milk production and decreases milk quality (Hernandez et al., 2011).

The activation of the immune system that concurs with the beginning of the dry period recruits blood leukocytes but they do not reach the mammary gland until $6 \mathrm{~d}$ after the onset of dry off and their concentrations are still below protective levels at $\mathrm{d} 8$ after drying off (Burvenich et al., 2007). To avoid the high risk of mastitis in this period, antibiotics are routinely infused into the mammary gland at dry off; however, this practice is associated with the risk of developing antimicrobial resistance to antibiotics. Stimulation of animal immunity at the beginning of the dry period may be relevant not only to improve the efficacy of antibiotic treatment, especially in cases of infection with bacteria escaping spectrum antibiotics (Erskine et al., 2003), but also to avoid the use of antibiotics as preventive agents. Moreover, reducing the duration of the dry period under $60 \mathrm{~d}$ without compromising milk yield has been an active area of discussion during the last years, as it would greatly increase the efficiency of dairy farms by reducing the number of unproductive days (De Vries et al., 2010).

Mammary serum amyloid A3 (M-SAA3) is an acute phase protein that participates in the innate immune response. In contrast to other members of the family, it is specifically produced in the mammary gland, and it is present in high concentrations in colostrum and milk during infection processes and variable levels along the lactation period (McDonald et al., 2001; Molenaar et al., 2009; Saremi et al., 2013). Members of the family have been related to several immunological functions in the organism such as chemotaxis of immune cells (Badolato et al., 1994; de Jesus Rodriguez et al., 2009), cytokine modulation (Patel et al., 1998; He et al., 2003), opsonization of bacteria (Hari-Dass et al., 2005), organism protection against infection (Larson et al., 2003; Mack et al., 2003; Gardiner et al., 2009; Molenaar et al., 2009), and the activation of metalloproteinase expression in immune cells (Lee et al., 2005). Thus, we hypothesized that an intramammary infusion of MSAA3 at dry off might foster a more rapid and effective involution of the mammary gland and would reduce the risk of intramammary infections at that time.

The aim of this study was to evaluate the potential of the M-SAA3 protein as an activator of mammary gland involution during the early dry period. The effects of intramammary infusion of recombinant M-SAA3 were evaluated in different contexts. First, the effect of intramammary infusion of recombinant M-SAA3 on milk components was studied in vivo in dairy cows after drying off. Second, an in vitro study was carried out to determine the potential effect of the M-SAA3 in epithelial mammary cell and dendritic cell (DC) functions.

\section{MATERIALS AND METHODS}

\section{Recombinant M-SAA3 Production}

The EcUR206 strain [an Escherichia coli BL21 Star (DE3)-pET101/D-TOPO vector containing the goat MSAA3 sequence isolated in a previous study (Domènech et al., 2012)] was used in recombinant protein production. The process has been explained elsewhere (Domènech et al., 2012). Briefly, BL21/pURAD1 was grown in $400 \mathrm{~mL}$ of Luria Bertani-Ampicillin medium at an initial optical density at $600 \mathrm{~nm}\left(\mathbf{O D}_{600}\right)$ of 0.05 until log phase was achieved. Recombinant expression was induced by isopropyl $\beta$-D-1-thiogalactopyranoside (IPTG) $0.1 \mathrm{~m} M$ for $80 \mathrm{~min}$. A cell pellet was obtained by centrifugation at $6,000 \times g$ for $10 \mathrm{~min}$, and frozen at $-80^{\circ} \mathrm{C}$ until use. Cell pellets were resuspended to an $\mathrm{OD}_{600}=100$ in $20 \mathrm{mM} \mathrm{Na} \mathrm{HPO}_{4} / \mathrm{NaH}_{2} \mathrm{PO}_{4}, 0.5 \mathrm{M}$ $\mathrm{NaCl}, \mathrm{pH} 7.4$ buffer containing lysozyme $(0.2 \mathrm{mg} / \mathrm{mL})$, DNase I and RNase A (20 $\mu \mathrm{g} / \mathrm{mL})$, a cocktail inhibitor of proteases $(1 \mathrm{~m} M)$, and $\mathrm{MgCl}_{2}(1 \mathrm{~m} M)$ during $30 \mathrm{~min}$ at room temperature (RT). The suspension was mixed with preweighed $0.1-\mathrm{mm}$ glass beads (range $26-36 \mathrm{mg} /$ $\mathrm{mL}$ of sample; Biospec Products Inc., Bartlesville, OK). Three cycles of beating of $45 \mathrm{~s}$ each, with $1 \mathrm{~min}$ on ice within cycles, were carried out in the MiniBead Beater (Biospec Products Inc.). The disrupted cell suspension was centrifuged for $15 \mathrm{~min}$ at $20,000 \times g$ at $4^{\circ} \mathrm{C}$ and the supernatant containing the soluble recombinant protein was recovered. Recombinant protein was purified with commercial His SpinTrap columns (GE Healthcare, Uppsala, Sweden), following manufacturer's instructions. The purified protein was dialyzed overnight at $4^{\circ} \mathrm{C}$ against $\mathrm{PBS}$ and it was further quantified using spectrophotometry $\left[\left(\mathrm{A}_{280} \times\right.\right.$ molecular weight $) /$ extinc- 
tion coefficient in milligrams per milliliter]. Lipopolysaccharide traces in the eluted fraction were quantified by endoLISA endotoxin assay (Hyglos). Final LPS levels corresponded to $0.08 \mathrm{ng}$ of LPS/ $\mu \mathrm{g}$ of recombinant protein. This level was similar to the traces observed in the recombinant commercial Apo-SAA (ProSci Inc., Poway, CA; LPS levels $<0.1 \mathrm{ng} / \mu \mathrm{g}$ of protein).

\section{Mammary Gland M-SAA3 Infusions}

Two quarters of 9 Holstein lactating cows (46.4 \pm 3.43 mo of age, lactation number $=1.5 \pm 0.23$, lactation length $=330.5 \pm 38.39 \mathrm{~d}$, and average milk production $=10,359 \pm 706.8 \mathrm{~kg}$ ) were infused at drying off, after the last milking, $t=0$. (Average milk production for the last $3 \mathrm{~d}$ before drying was $22.7 \pm$ $1.18 \mathrm{~kg} / \mathrm{d}$.) The infusion was performed via the teat canal using mammary cannulas with $1 \mathrm{mg}$ of M-SAA3 or $80 \mathrm{ng}$ E. coli LPS (Sigma Aldrich, Madrid, Spain) to reproduce the possible effect of LPS traces in purified recombinant SAA3 fraction. The same volume $(10 \mathrm{~mL})$ of saline solution was infused in the respective control quarters (front or back quarters). Immediately after treatment, all quarters received intramammary treatment with routine antibiotic [cloxacillin benzathine, 0.6 g; Orbenin Extra Dry Cow (Pfizer, Madrid, Spain)]. Front and back quarters were treated statistically independently. Milk samples were taken at $0800 \mathrm{~h}$ before intrammamary infusion $(t=0)$ and every day at 0800 $\mathrm{h}$ for 3 consecutive days $(t=1,2$, and 3$)$. Milk $(10 \mathrm{~mL})$ was frozen at $-20^{\circ} \mathrm{C}$ for metalloproteinases analyses and fresh milk was analyzed for SCC, fat, and protein content at ALLIC (Laboratori Interprofessional Lleter de Catalunya, Cabrils, Spain).

\section{Metalloproteinase Quantification by Zymography Gel}

The quantification of metalloproteinase activity was performed according to previous studies (FernandezResa et al., 1995). Frozen milk was thawed and centrifuged at $2,700 \times g$ for 10 min to obtain skim milk. Diluted 1:20 skim milk was mixed 1:1 with loading buffer $(0.125 M$ Tris $\mathrm{pH}=6.8$ with $0.005 \%$ bromophenol blue, $20 \%$ glycerol, $4 \%$ SDS) and electrophoresed in a $10 \%$ polyacrylamide gel containing $1 \mathrm{mg} / \mathrm{mL}$ porcine gelatin. Samples were run for $1 \mathrm{~h}$ at $150 \mathrm{~V}$ in running buffer (192 m $M$ Gly, $25 \mathrm{~m} M$ Tris, 0.1\% SDS). After running, gel was washed with $2.5 \%$ Triton X-100 solution at RT with gentle agitation for $30 \mathrm{~min}$. The gel was then incubated with developing buffer $(50 \mathrm{~m} M$ Tris $\mathrm{pH}$ 7.6 with $0.2 \mathrm{M} \mathrm{NaCl}, 5 \mathrm{mM} \mathrm{CaCl}, 0.02 \%$ Brij detergent (B4184, Sigma Aldrich) for $30 \mathrm{~min}$, and reincubated in fresh developing buffer for $48 \mathrm{~h}$ at $37^{\circ} \mathrm{C}$ without agitation. Gels were stained with Coomassie Blue R-250
(Bio-Rad, Madrid, Spain) for 30 min. Destaining buffer ( $50 \%$ methanol, $10 \%$ acetic acid) was used to visualize areas of digestion of the metalloproteinases that appeared as clear bands against a darkly stained background where the substrate had been degraded by the enzyme. Gels were digitalized and bands were analyzed with the Quantity One software (Bio-Rad, Madrid, Spain). The metalloproteinase activity was defined by the ratio INT: $\mathrm{mm}^{2}$, calculated by the Quantity One software regarding the intensity (INT) and size data of each band.

\section{Mammary Gland Primary Cultures}

Mammary gland tissue was obtained at slaughterhouse from the secretory tissue located above the gland cistern of lactating cow before drying off and transported in chilled PBS with $100 \mu \mathrm{g} / \mathrm{mL}$ of streptomycin, $100 \mathrm{U} / \mathrm{mL}$ of penicillin, and $2.5 \mu / \mathrm{mL}$ of amphotericin B. In the laboratory, tissue was cut into small pieces and incubated in Hanks' balanced salt solution (Life Technologies, Madrid, Spain) with $0.1 \mathrm{~m} M$ EDTA and $0.1 \mathrm{mM}$ dithiothreitol for $30 \mathrm{~min}$ at $37^{\circ} \mathrm{C}$ in $10 \%$ $\mathrm{CO}_{2}$ at $150 \mathrm{rpm}$. Then, supernatant was removed and RPMI-1640 medium with $0.05 \%$ collagenase was added and incubated for $30 \mathrm{~min}$. Medium contained epithelial cells, which were centrifuged at $300 \times g$ for 5 min. This process was repeated 3 times. Final cell pellets were resuspended in F-12 medium with $8 \mu \mathrm{g} /$ $\mathrm{mL}$ bovine insulin, $10 \mu \mathrm{g} / \mathrm{mL}$ gentamycin, $50 \mu \mathrm{g} / \mathrm{mL}$ hydrocortisone, $100 \mu \mathrm{g} / \mathrm{mL}$ streptomycin, $100 \mathrm{U} / \mathrm{mL}$ penicillin, and $2.5 \mu \mathrm{g} / \mathrm{mL}$ amphotericin. Cells were quantified by hemocytometer counting and incubated at 80,000 cells $/ \mathrm{cm}^{2}$ in flasks. Epithelial cell phenotype was confirmed by immunofluorescence staining against anti-cytokeratin antibodies (Sigma Aldrich) as previously described in the literature (Hashim et al., 2004). Mammary gland primary cells were grown on coverslips and fixed with $4 \%$ paraformaldehyde (Sigma Aldrich), diluted in PBS. HeLa cells (European Collection of Cell Cultures, Salisbury, UK) were used as positive control and macrophage differentiated THP-1 cells (European Collection of Cell Cultures) as negative control. Coverslips were blocked with $150 \mu \mathrm{L}$ of PBS containing goat serum $(0.05 \% \mathrm{vol} / \mathrm{vol})$ and Triton $0.2 \%$, for $30 \mathrm{~min}$ at RT. Primary antibody (monoclonal anti-cytokeratin pan antibody produced in mouse, Sigma-Aldrich, 1:500 dilution) was incubated in blocking buffer for $2 \mathrm{~h}$ at RT. After 3 washes with PBS, secondary antibody (anti-mouse-FITC, Sigma-Aldrich, 1:1,000) was incubated for $1 \mathrm{~h}$ at RT. Finally, cells were washed and dried coverslips, mounted into glass slides using Fluoroprep (Biomerieux, Craponne, France) and observed in the fluorescence microscope. 


\section{Bovine Monocyte Isolation and Differentiation to Dendritic Cells}

Bovine blood with sodium heparin, $50 \mathrm{IU} / \mathrm{mL}$, as anticoagulant was obtained at slaughterhouse. The blood was diluted 1:1 with PBS with $2 \%$ fetal calf serum at RT. The diluted blood was layered onto Histopaque-1077 (Sigma Aldrich) at 1:2 ratio (Histopaque/ diluted blood) and centrifuged at $600 \times g$ (brakes off) for 30 min at RT. Peripheral blood mononuclear cells (PBMC) were isolated from the interface, washed with medium and centrifuged $10 \mathrm{~min}$ at $200 \times \mathrm{g}$. The cell pellet was resuspended and incubated with $10 \mathrm{~mL}$ of Red Blood Lysis buffer (Sigma Aldrich) and incubated for $10 \mathrm{~min}$ at RT. After centrifuging at $250 \times \mathrm{g}$ for 5 min, the process was repeated until a free-erythrocyte pellet was observed. The PBMC were resuspended in supplemented medium (RPMI, 10\% fetal calf serum, 50 $\mu M \beta$-mercapthoethanol, $1 \%$ penicillin/streptomycin) and quantified using a hemocytometer. The PBMC were incubated in a $75-\mathrm{cm}^{2}$ flask in a ratio of $10^{6}$ cells/ $\mathrm{cm}^{2}$, and incubated during $1.5 \mathrm{~h}$ in $5 \% \mathrm{CO}_{2}$ at $37^{\circ} \mathrm{C}$. After incubation, adherent monocytes were washed once with PBS and incubated with supplemented medium with IL-4 and granulocyte macrophage colony-stimulating factor cytokines (Bovine Dendritic Cell Growth kit, Bionova, Madrid, Spain; 1:20 dilution). Medium was changed at $\mathrm{d} 3$. The evolution of the dendritic cell (DC) morphology was evaluated at the microscope and the cell phenotype was checked by CD11c quantification. The day of the experiment, cells were scraped off and quantified. Cells were seeded in 24 -well plates at 400,000 DC/well and incubated with supplemented RPMI without antibiotics.

\section{Staphylococcus aureus Infection of Mammary Gland Primary Cultures}

Pathogenic Staphylococcus aureus was isolated from mastitic milk and kindly provided by Associació Interprofessional Lletera de Catalunya (Barcelona, Spain). Staphylococcus aureus was grown in nutrient medium and plated onto mannitol salt agar. Single colonies were grown in $10 \mathrm{~mL}$ of nutrient medium overnight at $37^{\circ} \mathrm{C}$ in static (not shaken) conditions. A cell pellet was obtained by centrifugation at $6,000 \times g$ for $10 \mathrm{~min}$ at $4^{\circ} \mathrm{C}$. The bacterial concentration was calculated by spectrophotometric quantification $\left(\mathrm{OD}_{600}=0.4\right.$ corresponds to $10^{7} \mathrm{cfu} / \mathrm{mL}$ ). Similar infective bacterial doses were obtained by resuspending and diluting the cell pellet with the corresponding medium without antibiotics.

Mammary epithelial cells were seeded in 24-well plates at 44,000 cells/well. Cells were preincubated with 30 $\mu \mathrm{g} / \mathrm{mL}$ of recombinant M-SAA3 for $1 \mathrm{~h}$. After preincubation, mammary cells were infected with $S$. aureus at $10^{6} \mathrm{cfu} / \mathrm{mL}$ for $2 \mathrm{~h}$. Cells were washed thoroughly with PBS and internalized $S$. aureus was released from cells using Triton $0.1 \%$. Bacteria were serially diluted and plated onto mannitol salt agar. Colonies were counted after overnight growth at $37^{\circ} \mathrm{C}$.

\section{M-SAA3 Treatment on Dendritic Cells and Mammary Epithelial Cells}

Mammary epithelial cells from primary cultures $(44,000$ cells/well $)$ and dendritic cells $\left(4 \cdot 10^{5}\right.$ cells/well $)$ were seeded in 24-well plates. Cells were incubated with the corresponding media without antibiotics, with and without $30 \mu \mathrm{g} / \mathrm{mL}$ of recombinant M-SAA3 for $3 \mathrm{~h}$. After washing with PBS, cells were resuspended with $0.5 \mathrm{~mL}$ of Trizol (Invitrogen, Madrid, Spain) and frozen at $-80^{\circ} \mathrm{C}$ until gene expression analyses by quantitative RT-PCR were performed.

\section{Quantitative RT-PCR}

Total RNA was extracted from epithelial mammary cells and DC using Trizol (Invitrogen) following manufacturer's instruction and quantified using Nanodrop (Bio-Rad, Hercules, CA). The RNA was retrotranscribed to DNA using IScript cDNA synthesis kit (BioRad, Hercules, CA). Quantitative (q)PCR was performed for genes encoding for $\beta$-actin, IL- 8, IFN $\gamma$, C-C chemokine receptor 7 (CCR7), cluster of differentiation 80 (CD80), IL-12, tumor necrosis factor- $\alpha$ (TNFo), and nitric oxide synthase (iNOS) using iQ5 Thermocycler (Bio-Rad) and qPCR conditions for each set of primers were individually optimized (Table 1 ). The specificity of the amplification was evaluated by the single band identification at the expected molecular weight in DNA agarose gel and a single peak in the qPCR melting curves. The efficiency was calculated by amplifying serial 1/10 dilutions of each gene amplicon. A standard curve of Ct versus log concentration was plotted to obtain the efficiency, which is calculated using the formula $10^{1 / \text { slope }}$, with an acceptable range of 1.8 to 2.2 (Chow et al., 2010). A total reaction volume of $20 \mu \mathrm{L}$ was used, containing $50 \mathrm{ng}$ of cDNA, $10 \mu \mathrm{L}$ of SYBR Green Fluorescent (Bio-Rad), and the optimized primer concentration for each gene (Table 1 ). The qPCR reactions were cycled as follows: an initial denaturing step of $10 \mathrm{~min}$ at $95^{\circ} \mathrm{C}$, followed by 40 cycles of $10 \mathrm{~s}$ at $95^{\circ} \mathrm{C}$, $15 \mathrm{~s}$ at the optimized annealing temperature for each gene, $30 \mathrm{~s}$ at $72^{\circ} \mathrm{C}$, and a final extension of $10 \mathrm{~min}$ at $72^{\circ} \mathrm{C}$. Relative gene expression was calculated using the $2^{\triangle \mathrm{Ct}}$ method with $A C T B$ as the reference gene. 
Table 1. Sequence, annealing temperature (At), concentration, and amplicon size of the forward and reverse primers used for quantitative PCR

\begin{tabular}{|c|c|c|c|c|c|}
\hline Gene & Forward $\left(5^{\prime}-3^{\prime}\right)$ & Reverse $\left(5^{\prime}-3^{\prime}\right)$ & At $\left({ }^{\circ} \mathrm{C}\right)$ & $\begin{array}{c}\text { Concentration } \\
(\mu M)\end{array}$ & $\begin{array}{l}\text { Amplicon } \\
\text { size (bp) }\end{array}$ \\
\hline$A C T B$ & CTGGACTTCGAGCAGGAGAT & CCCGTCAGGAAGCTCGTAG & 57 & 0.125 & 75 \\
\hline$I L-8$ & TTGAGAGTGGGCCACACTGTG & TGCACCCACTTTTCCTTGG & 55 & 0.5 & 100 \\
\hline CCR7 & AGCACGTGGAGGCCTTGAT & GCGGATGATGACGAGGTAGC & 50 & 0.5 & 100 \\
\hline$C D 80$ & GAACCGCACCATCACTGACA & TAATGGTCCAGGTCAGGTGC & 56 & 0.25 & 484 \\
\hline$I L-12$ & GAGGCCTGTTTACCACTGGA & CTCATAGATACTTCTAAGGCACAG & 50 & 0.3125 & 140 \\
\hline
\end{tabular}

\section{Statistical Analyses}

Somatic cell count, fat, protein, metalloproteinase activity, and gene expression were analyzed using a mixed-effects linear model (SAS Inst. Inc., Cary, NC). For the in vivo experiment, treatment, quarter, day, and the interaction between treatment and day and treatment and quarter were used as fixed effects. Time 0 was used as covariate and day as a repeated measure. The model also accounted for the random effects of animal within treatment. Data were previously transformed when necessary to achieve a normal distribution. Results are expressed as the means of nontransformed data \pm SEM (except otherwise stated).

\section{RESULTS}

\section{Mammary SAA3 Effect on Metalloproteinase Activity, SCC, Fat, and Protein Contents After Mammary Gland Infusion}

Milk metalloproteinase activity for MMP-9 and MMP-2 was quantified using zymography gels. Clear bands were observed at $92 \mathrm{kDa}$ (MMP-9) and $72 \mathrm{kDa}$ (MMP-2). These bands represent the enzymatic activity, because they reflect the amount of substrate digested by the enzymes present in the sample. A significant M-SAA3 treatment effect was observed in the MMP-9 activity $(P<0.01$; Figure 1a). The M-SAA3 increased $(P<0.0001)$ the activity of MMP-9 during the $3 \mathrm{~d}$ of experiment compared with the saline solution (data represented as root INT. $\mathrm{mm}^{2} ; \mathrm{d} 1: 16.1 \pm 1.6$ vs. $5.6 \pm 1.6$; d $2: 12.4 \pm 1.6$ vs. $6.9 \pm 1.6$; d $3: 12.9 \pm 1.6$ vs. $6.91 \pm$ 1.6, for M-SAA3 and saline solution, respectively). The M-SAA3 infusion also increased $(P<0.01)$ the levels of MMP-9 activity compared with LPS (d 1: $16.1 \pm 1.6$ vs. $12.1 \pm 1.8 ; \mathrm{d} 2: 12.4 \pm 1.6$ vs. $9.1 \pm 1.8 ; \mathrm{d} 3: 13.9 \pm 1.6$ vs. $8.3 \pm 1.8$, for M-SAA3 and LPS, respectively; Figure $2)$. In contrast, no differences were found between LPS and their negative control (d 1: $12.1 \pm 1.8$ vs. $8.4 \pm 1.8$; d $2: 9.1 \pm 1.8$ vs. $8.6 \pm 1.8$; d $3: 8.3 \pm 1.8$ vs. $7.3 \pm 1.8$, for LPS and saline solution, respectively). The MMP-2 activity remained unaltered after treatment either with M-SAA3 or LPS (Figure 1b).

No differences in milk SCC (Figure 2a) were found between quarters infused with M-SAA3 compared with those infused with saline solution (data represented as $\mathrm{SCC} / \mathrm{mL} \pm \mathrm{SEM}$, where SEM corresponded to the standard error of the mean of log-transformed data; d 2: $2.76 \times 10^{6} \pm 0.67$ vs. $5.98 \times 10^{5} \pm 0.66$, for M-SAA3 and saline solution, respectively) and LPS (d 2: $2.76 \times$ $10^{6} \pm 0.67$ vs. $9.60 \times 10^{5} \pm 0.73$, for M-SAA3 and LPS, respectively).

A treatment effect was observed $(P<0.01)$ for fat concentration (Figure 2b). The M-SAA3 increased $(P$ $<0.01$ ) milk fat concentration compared with the respective negative control (data represented as percentage of fat; $d$ 1: $1.42 \pm 0.23 \%$ vs. $1.14 \pm 0.23 \%$; d 2: 1.88 $\pm 0.23 \%$ vs. $1.12 \pm 0.23 \%, \mathrm{~d} 3: 1.77 \pm 0.23 \%$ vs. $0.13 \pm$ $0.23 \%$, for M-SAA3 and saline solution, respectively). In addition, fat concentration was not increased by LPS treatment compared with its negative control. Milk protein concentration tended $(P=0.05)$ to be affected by M-SAA3 treatment (Figure 2c). The M-SAA3 tended to increase milk protein concentration compared with the negative control (data represented as percentage of protein; d 1: $0.66 \pm 0.03 \%$ vs. $0.58 \pm 0.03 \%$; d $2: 0.74$ $\pm 0.03 \%$ vs. $0.67 \pm 0.03 \%, \mathrm{~d} 3: 0.80 \pm 0.03 \%$ vs. $0.73 \pm$ $0.03 \%$, for M-SAA3 and saline solution, respectively). Protein content in M-SAA3-treated quarters tended to be also greater than in the LPS quarters (d 1: $0.66 \pm$ $0.03 \%$ vs. $0.60 \pm 0.03 \%$; $2: 0.74 \pm 0.03 \%$ vs. $0.70 \pm$ $0.03 \%$, d 3: $0.80 \pm 0.03 \%$ vs. $0.74 \pm 0.04 \%$, for M-SAA3 and LPS, respectively). Protein content with LPS did not differ from its negative control.

\section{Mammary SAA3 Increased IL-8 and TNFa Expression and Inhibited the Translocation of S. aureus in Mammary Gland Primary Cultures}

A 15 -fold increased expression of IL-8 $(P<0.01)$ was observed after $3 \mathrm{~h}$ incubation with M-SAA3 (data represented as relative gene expression, $0.006 \pm 0.001$ vs. $0.00039 \pm 0.00038$, for M-SAA3 and negative 
a

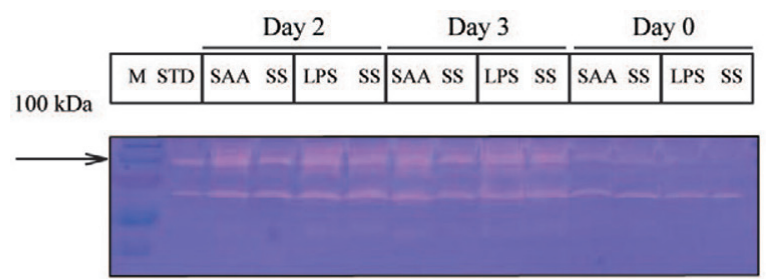

b
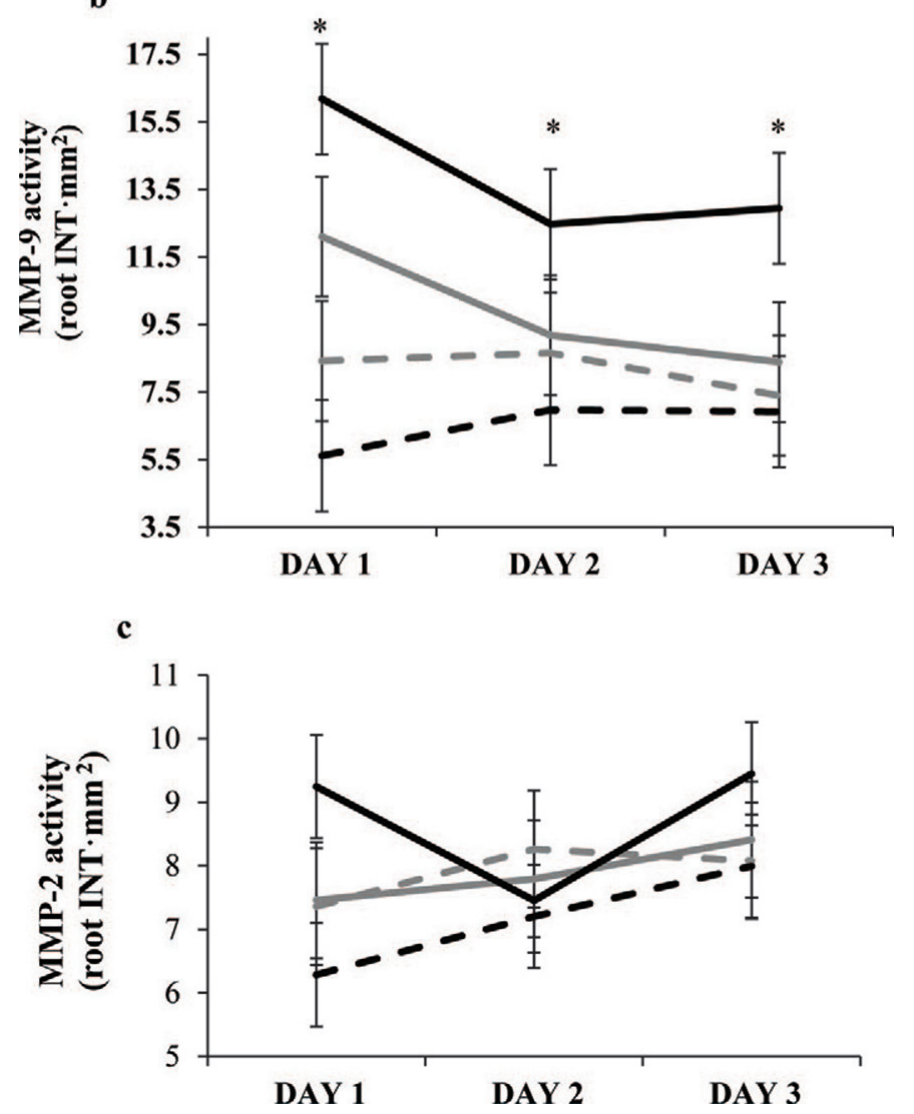

Figure 1. Mammary metalloproteinase MMP-9 (a, b) and MMP-2 $(\mathrm{a}, \mathrm{c})$ activity during the early dry period of dairy cows. Enzymatic activity of MMP-9 and MMP-2 in zymography gels (a) detected as clear bands of $92 \mathrm{kDa}$ and $72 \mathrm{kDa}$ respectively. The loaded samples are (from left to right): protein ladder (M), milk standard (STD), and mammary secretion of M-SAA3 or LPS treated quarter (SAA or LPS) paired with the mammary secretion of saline control quarter (SS), at d 2, 3, or 0 of treatment. Quantification of MMP-9 (b) and MMP-2 (c) activity in zymography gels. Solid black lines are M-SAA3 treatment, dashed black lines are M-SAA3 saline control, solid gray lines are LPS treatment, and dashed gray lines are LPS saline control. Asterisks indicate significant differences $(P<0.05)$. Color version available in the online PDF.

control respectively; Figure 3d). Furthermore, TNFo levels were increased from nondetectable levels to easily detectable levels (data represented as relative gene expression, $0.0006 \pm 0.0001$ vs. nondetectable levels, for M-SAA3 and negative control, respectively).
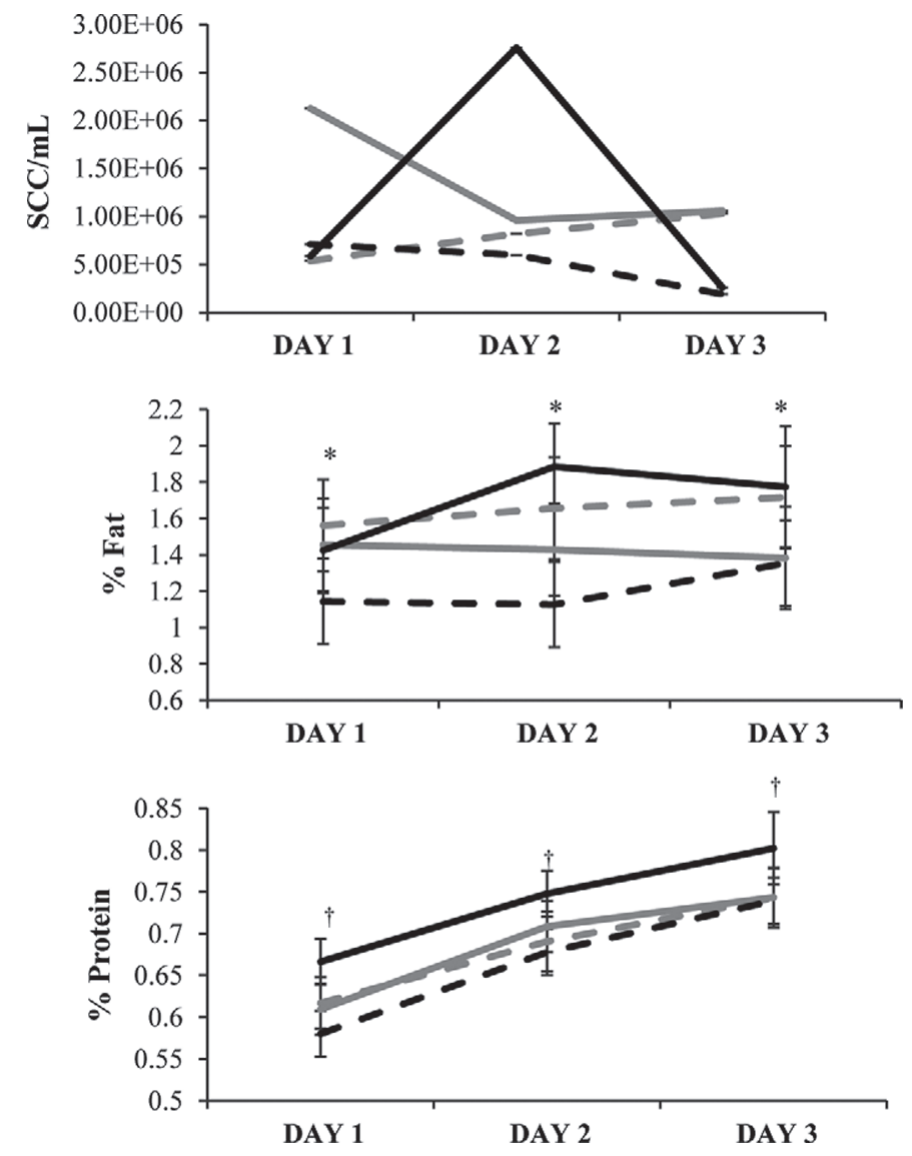

Figure 2. Somatic cell count (a), fat (b), and protein concentration (c) in mammary secretions during the early dry period of dairy cow. Somatic cell counts are represented as $\mathrm{SCC} / \mathrm{mL} \pm \mathrm{SEM}$ (transformed data); fat and protein concentration data are represented as percentage \pm SEM during the $3 \mathrm{~d}$ after dry off. Solid black lines are M-SAA3 treatment, dashed black lines are M-SAA3 saline control, solid gray lines are LPS treatment, and dashed gray lines are LPS saline control. Asterisks indicates significant differences $(P<0.05)$ between treatments, and daggers $(\dagger)$ indicate a tendency to be different $(P<0.1)$.

Mammary gland primary cultures preincubated with or without M-SAA3 were challenged with a pathogenic strain of $S$. aureus isolated from mastitic milk. The MSAA3 decreased $(P<0.05)$ the bacterial translocation up to $25 \%\left(2.4 \times 10^{5} \pm 2.9 \times 10^{4} \mathrm{cfu} / \mathrm{mL}\right.$ vs. $3.3 \times 10^{5}$ $\pm 2.9 \times 10^{4} \mathrm{cfu} / \mathrm{mL}$, for M-SAA3 and control, respectively; Figure 3e).

\section{Mammary SAA3 Promoted DC Activation and Maturation}

During differentiation from monocytes, the CD11c gene tended to increase, and was greater after Salmonella Dublin challenge (data not shown). Expression of IL-8 increased $(P<0.01) 2$-fold (data represented as relative gene expression, $1.06 \pm 0.08$ vs. $0.48 \pm 0.01$, for M-SAA3 and negative control, respectively) after treat- 
a

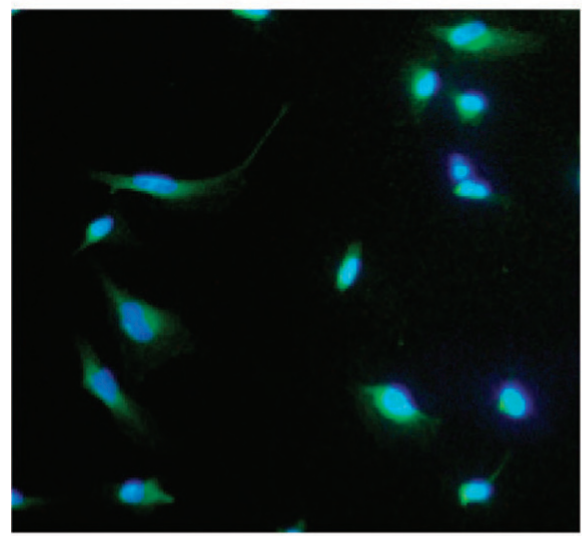

d

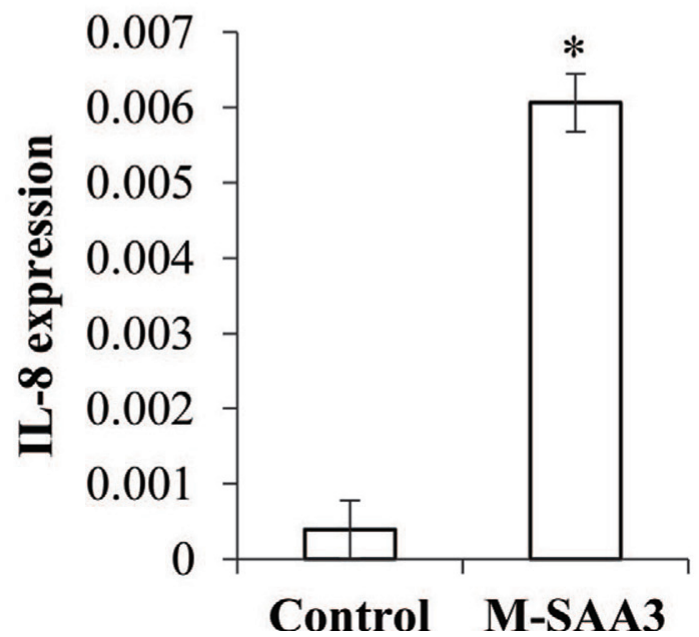

b

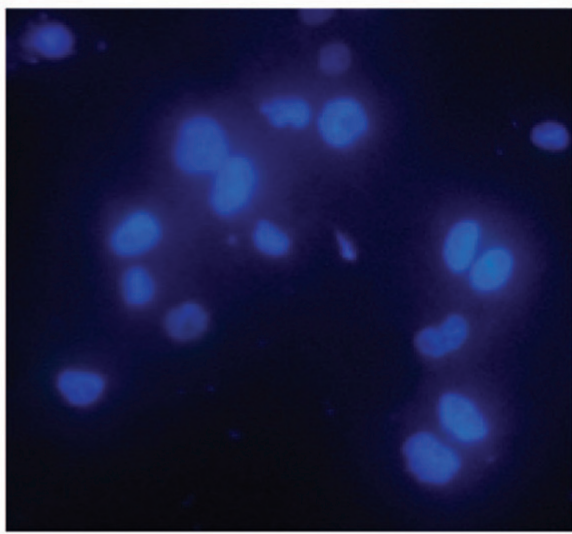

e

\section{e}

c

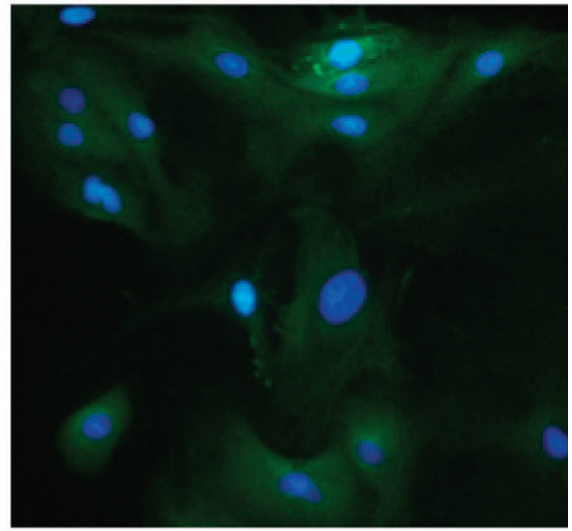

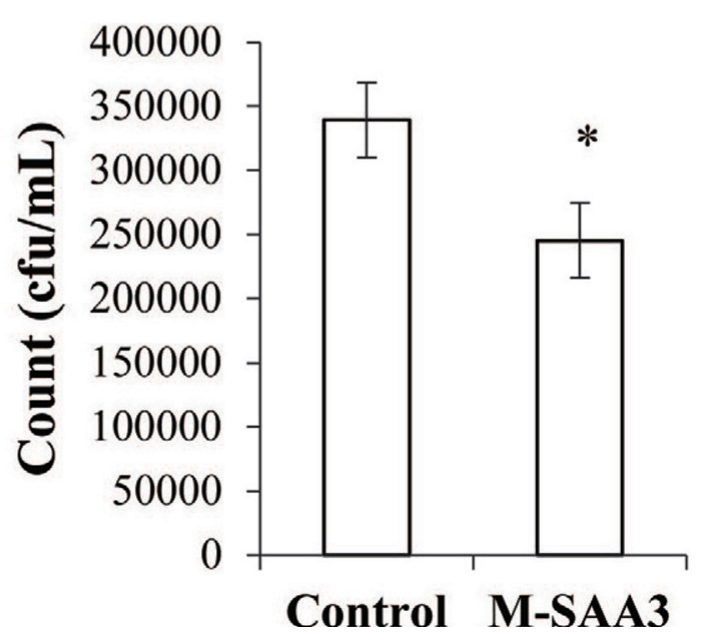

Figure 3. Immunofluorescence of primary mammary cultures with pan-cytokeratin: HeLa cells (a) as positive control, THP-1 macrophages (b) as negative control, and mammary cultures (c). IL-8 gene expression (d) and viable cell counts of internalized $S$. aureus (e). Bars represent means \pm SEM. Asterisks indicate significant differences $(P<0.05)$. Color version available in the online PDF.

ment with M-SAA3. Expression of INF $\gamma$ was highly upregulated $(P<0.01)$, obtaining levels 28 -fold greater $(0.002 \pm 0.001$ vs. $0.00007 \pm 0.00041$, for M-SAA3 and negative control, respectively). The expression of TNF $\alpha$ increased $(P<0.01)$ by 7 -fold $(0.07 \pm 0.01$ vs. $0.01 \pm$ 0.01, for M-SAA3 and negative control, respectively). The CCR7 marker increased $(P<0.01) 2.5$-fold $(0.018$ \pm 0.002 vs. $0.007 \pm 0.002$, for M-SAA3 and negative control respectively). The CD80 marker tended $(P=$ $0.05)$ to increase 3 -fold $(0.00045 \pm 0.0010$ vs. 0.00014 \pm 0.00010 , for M-SAA3 and negative control, respectively). Finally, iNOS expression tended $(P=0.05)$ to increase 3 -fold $(0.09 \pm 0.02$ vs. $0.03 \pm 0.02$; Figures $4 a-4 f)$.

\section{DISCUSSION}

This study points out the potential of M-SAA3 to increase the rate of mammary gland involution and modify the immune response during the early dry period. Each quarter of the mammary gland was used as an independent unit because the existence of local udder regulatory mechanisms involved in the regulation of milk production has been demonstrated in the bovine mammary gland (Svennersten et al., 1990). Moreover, in the context of the mammary gland involution and the optimization of the dry period, different studies have also proved that each quarter performs as independent unit regarding the stimulation of immune regulators 
a
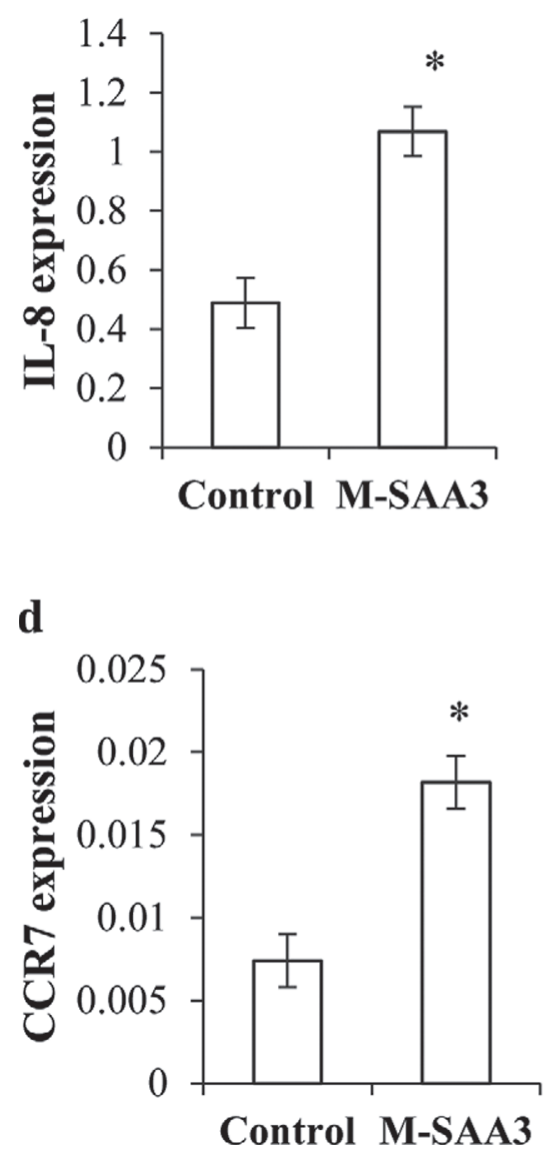

b

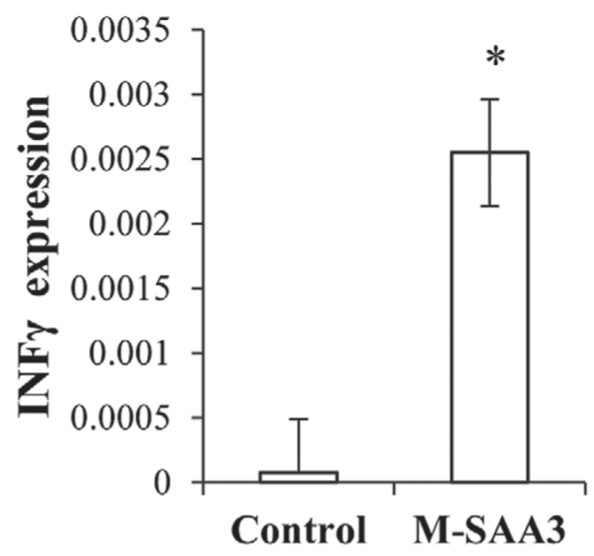

e

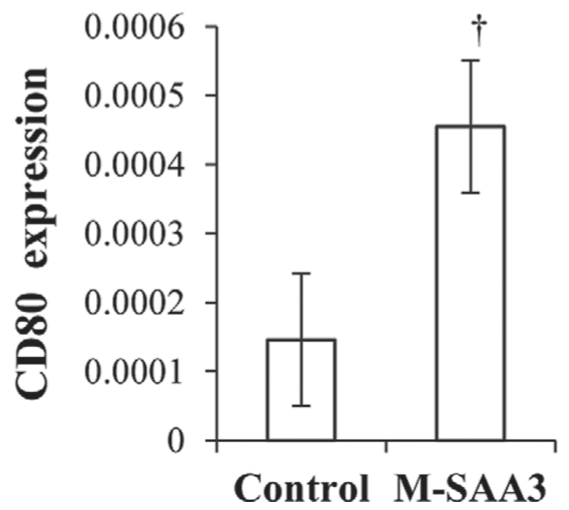

c

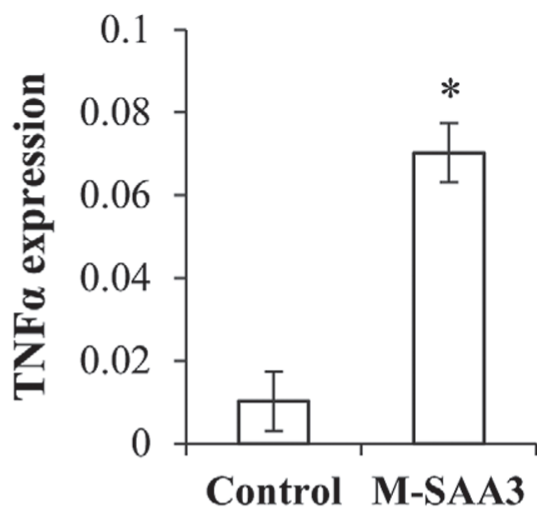

f

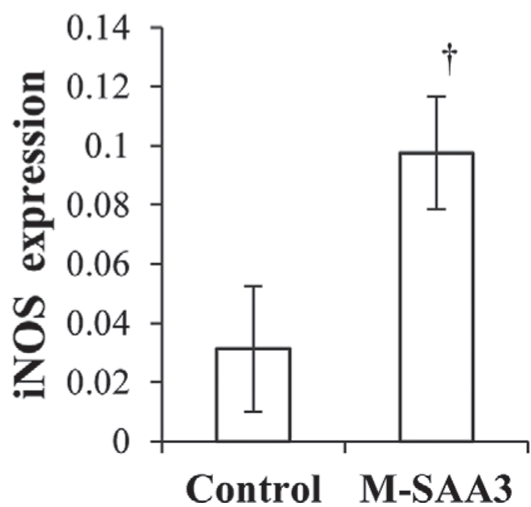

Figure 4. Gene expression of IL-8 (a), INFy (b), TNFo (c), CCR7 (d), CD80 (e), and iNOS (f) in dendritic cells. Bars represent the means \pm SEM for the different treatments. Asterisks indicates significant differences $(P<0.05)$ between treatments, and daggers $(\dagger)$ indicate a tendency to be different $(P<0.1)$.

such as lactoferrin or leukocytes infiltration, synthesis of metalloproteinases, and tissue remodeling, indicated by an independent increase in the permeability of the tight junctions and expression of pro-apoptotic factors in separate quarters (Wedlock et al., 2004; Dallard et al., 2011; Ponchon et al., 2014). The infusion of MSAA3 clearly increased the MMP-9 activity on milk during early dry period. The activity levels of MMP-9 (Figure 1a) were greater after $24 \mathrm{~h}$ postinfusion compared with saline control and remained beyond the basal levels during all the experiment. Lipopolysaccharide is a major constituent of the gram-negative cell wall, and highly activates immune response. During the M-SAA3 production, residual LPS traces were detected in the final eluted protein. Thus, the LPS traces had to be evaluated, as the bovine mammary gland is highly sensitive to low doses of LPS (Burvenich et al., 2007). However, infusion of pure traces of LPS did not increase the MMP-9 activity compared with negative control.
On the other hand, MMP-2 activity was not affected by MSAA-3 or LPS (Figure 1b). Metalloproteinases play a key role during the onset of the early involution, as they promote the degradation of the basement membrane of the mammary gland (Rabot et al., 2007). Metalloproteinase-9 has been described as the most active metalloproteinase participating in the involution process of the mammary gland in cows, and the main source of MMP-9 is considered to be the neutrophils (Yu et al., 2012). Levels of MMP-2 have been described to increase during mammogenesis and also during the late involution, the endothelial cells being the major MMP-2 producers in cows (Rabot et al., 2007).

Only numerical changes in SSC counts were observed in the M-SAA3-infused quarters (Figure 2a) during the second day of the experiment. Somatic cell counts mainly refer to the quantification of milk leukocytes, that is, polymorphonuclear neutrophils, macrophages, and lymphocytes. In addition, a small percentage of 
epithelial cells count toward this term (Paape et al. 2002). Somatic cells normally increase during the involution process ( $\mathrm{Yu}$ et al., 2012), as immune response mediators are attracted from blood vessels. An increase in immune response mediators would help to protect the mammary gland against infections, and also to increase the activity of MMP-9.

Milk fat and protein concentrations (Figures $2 \mathrm{~b}$ and 2c) were both increased in the M-SAA3 treatment in the early dry period. Although expression of milk-specific proteins is decreased during drying off, the total protein content increases. This is due in part because of water reabsorption, but mainly to a direct passage of serum-derived proteins. During the early dry period, there is an increased permeability of the epithelial cell barrier, which facilitates the passage of high concentrations of lactoferrin, serum albumin, and immunoglobulins to and from the blood (Hurley and Rejman, 1993). The amount of M-SAA3 inoculated would not itself increase the concentrations obtained in the secretions because only $1 \mathrm{mg}$ is added and the protein levels are much higher. For instance, levels of lactogenic proteins in the first day of drying off vary from 4 to $17 \mathrm{mg} / \mathrm{mL}$ (Watanabe et al., 2008).

Concentrations of milk fat decline slowly during the first 2 to $3 \mathrm{wk}$ of the dry period but it is possible that greater fat accumulation is detected in the M-SAA3 quarter samples because of the lipid binding capacity of the protein (Liang and Sipe, 1995).

The expression profile of endogenous M-SAA3 in cow mammary gland has been described to be similar to that of lactoferrin and inversely related to lactogenicrelated proteins such as lactalbumin. High expression levels are observed during pregnancy and after calving and low levels during lactation. Typically, M-SAA3 levels increase $72 \mathrm{~h}$ after milking cessation (Molenaar et al., 2009). These data suggest that under normal conditions, M-SAA3 would already be participating in the mammary gland integrity. According to this, an intramammary infusion of exogenous M-SAA3 at the onset of the dry period would stimulate the involution process.

The numerical SCC increase during $d 2$ of the experiment (Figure 2a) suggested that M-SAA3 could be promoting cell chemotaxis (Hari-Dass et al., 2005). This is in agreement with previous data which indicated that hepatic SAA forms activated migration of monocytes and polymorphonuclear cells to the site of inflammation (Badolato et al., 1994). This chemotactic attraction could be mediated by IL-8, which main function is related to the attraction of immune response mediators (Baggiolini and Clark-Lewis, 1992). The expression of IL-8 in mammary epithelial cells increased dramatically (Figure 3a), indicating that the mammary gland epithelial cells were able to release a chemotactic cytokine after M-SAA3 exposure. Other cell types such monocytes and neutrophils have been also described to produce IL- 8 in response to members of the SAA family (He et al., 2003; Ribeiro et al., 2003; Lee et al., 2009).

Moreover, primary mammary gland cultures were challenged with a pathogenic strain of $S$. aureus isolated from mastitic milk. Interestingly, M-SAA3 decreased the bacterial infection by $25 \%$ (Figure 3e). Mastitis is the main cause of economic losses in dairy farms - more than $\$ 2$ billion per year in United States (Rainard, 2005). In addition, S. aureus infection is one of the major pathogens producing mastitis and one of the most difficult to control by antibiotic treatment (Rainard, 2005). We have previously reported that MSAA3 inhibited the internalization of enteropathogenic E. coli in an intestinal CaCo-2 cell line. Other authors have described that recombinant SAA1/2 inhibited the biofilm formation of uropathogenic E. coli (Erman et al., 2012). Adhesion to the epithelium is a critical step in mastitis produced by $S$. aureus. Most of the pathogenic $S$. aureus produce biofilms, which are indeed related to decreased antibiotic sensitivity (Vasudevan et al., 2003).

Additionally, M-SAA3 effects were tested in DC. The DC are effective antigen-presenting cells, with a key role in the onset of the adaptive immune response. The DC may be the only cell type able to activate naïve $\mathrm{T}$ cells (Banchereau and Steinman, 1998). Circulating immature DC in the blood stream enter into tissues, where they become resident cells. In the mammary gland, DC populations have been identified among alveoli, epithelia, and interalveolar tissue (Maxymiv et al., 2012). Immature DC present a high phagocytic activity and are responsible for antigen uptake. Maturation is reached, among other stimulus, by bacterial recognition. Mature DC slightly reduce the phagocytic activity and enhance other features such antigen presentation and the capacity to migrate toward secondary lymphatic nodes (Banchereau and Stenman, 1998; Banchereau et al., 2000). Maturation can be detected by an increase of related molecules such as CD80 and CCR7 (Zhao et al., 2006; Xia et al., 2009; Facci et al., 2010). The CD80 is an important co-stimulatory molecule that participates in the antigen presentation along with the major histocompatibility complex II. The CCR7 is a receptor that helps the migration of mature DC. The infused M-SAA3 increased several maturation markers related to DC activation, migration, and antigen presentation (Figures 4a-4f). Moreover, proinflammatory cytokines such as IL-8, INF $\gamma$, and TNF $\alpha$ were upregulated. The CCR7 and CD80 markers were also increased. Finally, the expression of the enzyme iNOS was also raised under M-SAA3 treatment. These results are in agree- 
ment with published data in which serum amyloid A treatment increased nitric oxide in macrophages (Sandri et al., 2008), a mediator that participates in the fight against pathogens, and it is produced by iNOS (Bogdan, 2001).

In summary, M-SAA3 promotes an increase of factors that participate in the mammary involution process, such as MMP-9 activity and upregulates the expression of IL-8 cytokine in primary mammary gland cultures. Moreover, M-SAA3 inhibits S. aureus invasion, helping to control the increased risk of intramammary infections during early dry off and directly participating in the immune response by activating the maturation of dendritic cells.

\section{CONCLUSIONS}

Recombinant M-SAA3 infusion acted as an activator of the mammary involution process and increased immune response mediators. Therefore, infusing M-SAA3 could represent a possible strategy to effectively accelerate mammary involution in cows and potentially shorten the dry period.

\section{ACKNOWLEDGMENTS}

We are indebted to the Cell Culture Unit of Servei de Cultius i Producció d'Anticossos i Citometria at the Autonomous University of Barcelona (Barcelona, Spain). The authors thank the Ruminant Production Department for helpful technical assistance and discussions. This study has been funded by INIA-MICINN (RTA2008-00050-C02-01).

\section{REFERENCES}

Annen, E. L., M. A. Collier, M. A. McGuire, and J. L. Vicini. 2004 Effects of dry period length on milk yield and mammary epithelial cells. J. Dairy Sci. 87(E-Suppl.):E66-E76.

Baggiolini, M., and I. Clark-Lewis. 1992. Interleukin-8, a chemotactic and inflammatory cytokine. FEBS Lett. 307:97-101.

Banchereau, J., F. Briere, C. Caux, J. Davoust, S. Lebecque, Y. J. Liu, B. Pulendran, and K. Palucka. 2000. Immunobiology of dendritic cells. Annu. Rev. Immunol. 18:767-811.

Banchereau, J., and R. M. Steinman. 1998. Dendritic cells and the control of immunity. Nature 392:245-252.

Bogdan, C. 2001. Nitric oxide and the immune response. Nat. Immunol. 2:907-916.

Boudreau, N., C. J. Sympson, Z. Werb, and M. J. Bissell. 1995. Suppression of ICE and apoptosis in mammary epithelial cells by extracellular matrix. Science 267:891-893.

Burvenich, C., D. D. Bannerman, J. D. Lippolis, L. Peelman, B. J. Nonnecke, M. E. Kehrli, and M. J. Paape. 2007. Cumulative physiological events influence the inflammatory response of the bovine udder to Escherichia coli infections during the transition period. J. Dairy Sci. 90 (E Suppl. 1):39-54.

Capuco, A. V., and R. M. Akers. 1999. Mammary involution in dairy animals. J. Mammary Gland Biol. Neoplasia 4:137-144.

Capuco, A. V., R. M. Akers, and J. J. Smith. 1997. Mammary growth in Holstein cows during the dry period: Quantification of nucleic acids and histology. J. Dairy Sci. 80:477-487.
Chow, A. W., J. F. Liang, J. S. Wong, Y. Fu, N. L. Tang, and W. H. Ko. 2010. Polarized secretion of interleukin (IL)-6 and IL- 8 by human airway epithelia 16HBE14o-cells in response to cationic polypeptide challenge. PLoS ONE 5:e12091.

Dallard, B. E., C. Baravalle, C. Andreotti, H. H. Ortega, V. Neder, and L. F. Calvinho. 2011. Intramammary inoculation of Panax ginseng extract in cows at drying off enhances early mammary involution. J. Dairy Res. 78:63-71.

de Jesus Rodriguez, B., C. Chevaleyre, G. Henry, D. Mollé, I. Virlogeux-Payant, M. Berri, F. Boulay, J. Léonil, F. Meurens, and H. Salmon. 2009. Identification in milk of a serum amyloid A peptide chemoattractant for B lymphoblasts. BMC Immunol. 10:4.

De Vries, L. D., H. Dover, T. Casey, M. J. VandeHaar, and K. Plaut 2010. Characterization of mammary stromal remodeling during the dry period. J. Dairy Sci. 93:2433-2443.

Domènech, A., J. G. Raynes, E. M. Rodríguez, A. Arís, A. Bach, and A. Serrano. 2012. Recombinant expression of goat milk serum amyloid A: Preliminary studies of the protein and derived peptides on macrophage phagocytosis. Protein Pept. Lett. 19:299-307.

Erman, A., K. Lakota, K. Mrak-Poljsak, M. G. Blango, V. KrizanHergouth, M. A. Mulvey, S. Sodin-Semrl, and P. Veranic. 2012. Uropathogenic Escherichia coli induces serum amyloid A in mice following urinary tract and systemic inoculation. PLoS ONE 7:e32933.

Erskine, R. J., S. Wagner, and F. J. DeGraves. 2003. Mastitis therapy and pharmacology. Vet. Clin. North Am. Food Anim. Pract. 19:109-138.

Facci, M. R., G. Auray, R. Buchanan, J. Kessel, D. R. Thompson, S. Mackenzie-Dyck, L. A. Babiuk, and V. Gerdts. 2010. A comparison between isolated blood dendritic cells and monocyte-derived dendritic cells in pigs. Immunology 129:396-405.

Fernandez-Resa, P., E. Mira, and A. R. Quesada. 1995. Enhanced detection of casein zymography of matrix metalloproteinases. Anal. Biochem. 224:434-435.

Gardiner, G. E., S. O'Flaherty, P. G. Casey, A. Weber, T. McDonald, M. Cronin, C. Hill, R. P. Ross, C. G. Gahan, and F. Shanahan 2009. Evaluation of colostrum-derived human mammary-associated serum amyloid A3 (M-SAA3) protein and peptide derivatives for the prevention of enteric infection: In vitro and in murine models of intestinal disease. FEMS Immunol. Med. Microbiol. 55:404-413.

Hari-Dass, R., C. Shah, D. J. Meyer, and J. G. Raynes. 2005. Serum amyloid A protein binds to outer membrane protein A of gramnegative bacteria. J. Biol. Chem. 280:18562-18567.

Hashim, A., M. Clyne, G. Mulcahy, D. Akiyoshi, R. Chalmers, and B. Bourke. 2004. Host cell tropism underlies species restriction of human and bovine Cryptosporidium parvum genotypes. Infect. Immun. 72:6125-6131.

He, R., H. Sang, and R. D. Ye. 2003. Serum amyloid A induces IL-8 secretion through a $\mathrm{G}$ protein-coupled receptor, FPRL1/LXA4R. Blood 101:1572-1581.

Hernandez, L. L., J. L. Collier, A. J. Vomachka, R. J. Collier, and N. D. Horseman. 2011. Suppression of lactation and acceleration of involution in the bovine mammary gland by a selective serotonin reuptake inhibitor. J. Endocrinol. 209:45-54.

Hurley, W. L., and J. J. Rejman. 1993. Bovine lactoferrin in involuting mammary tissue. Cell Biol. Int. 17:283-289.

Larson, M., H. Wei Shu, A. Weber, D. Mack, and T. McDonald. 2003. Human serum amyloid A3 peptide enhances intestinal MUC3 expression and inhibits EPEC adherence. Biochem. Biophys. Res. Commun. 300:531-540.

Lee, H. Y., M. K. Kim, K. S. Park, Y. H. Bae, J. Yun, J. I. Park, J. Y. Kwak, and Y. S. Bae. 2005. Serum amyloid A stimulates matrix-metalloproteinase-9 upregulation via formyl peptide receptor like-1-mediated signaling in human monocytic cells. Biochem. Biophys. Res. Commun. 330:989-998.

Lee, H. Y., S. D. Kim, J. W. Shim, S. Y. Lee, J. Yun, and Y. S. Bae 2009. LL-37 inhibits serum amyloid A-induced IL-8 production in human neutrophils. Exp. Mol. Med. 41:325-333. 
Liang, J. S., and J. D. Sipe. 1995. Recombinant human serum amyloid A (apoSAAp) binds cholesterol and modulates cholesterol flux. J. Lipid Res. 36:37-46.

Lin, C. Q., and M. J. Bissell. 1993. Multi-faceted regulation of cell differentiation by extracellular matrix. FASEB J. 7:737-743.

Mack, D., T. McDonald, M. Larson, W. Shu, and A. Webber. 2003 The conserved TFLK motif of mammary-associated serum amyloid A3 is responsible for up-regulation of intestinal Muc3 mucin expression in vitro. Pediatr. Res. 53:137-142.

Maxymiv, N. G., M. Bharathan, and I. K. Mullarky. 2012. Bovine mammary dendritic cells: A heterogeneous population, distinct from macrophages and similar in phenotype to afferent lymph veiled cells. Comp. Immunol. Microbiol. Infect. Dis. 35:31-38.

McDonald, T. L., M. A. Larson, D. R. Mack, and A. Weber. 2001. Elevated extrahepatic expression and secretion of mammary-associated serum amyloid A 3 (M-SAA3) into colostrum. Vet. Immunol. Immunopathol. 83:203-211.

Molenaar, A. J., D. P. Harris, G. H. Rajan, M. L. Pearson, M. R. Callaghan, L. Sommer, V. C. Farr, K. E. Oden, M. C. Miles, R. S. Petrova, L. L. Good, K. Singh, R. D. McLaren, C. G. Prosser, K. S. Kim, R. J. Wieliczko, M. H. Dines, K. M. Johannessen, M. R. Grigor, S. R. Davis, and K. Stelwagen. 2009. The acute-phase protein serum amyloid A3 is expressed in the bovine mammary gland and plays a role in host defence. Biomarkers 14:26-37.

Muschler, J., and C. H. Streuli. 2010. Cell-matrix interactions in mammary gland development and breast cancer. Cold Spring Harb. Perspect. Biol. 2:a003202.

Noble, M. S., and W. L. Hurley. 1999. Effects of secretion removal on bovine mammary gland function following an extended milk stasis. J. Dairy Sci. 82:1723-1730.

Paape, M., J. Mehrzad, X. Zhao, J. Detilleux, and C. Burvenich. 2002. Defense of the bovine mammary gland by polymorphonuclear neutrophil leukocytes. J. Mammary Gland Biol. Neoplasia 7:109-121.

Patel, H., S. Fellowes, S. Coade, and P. Woo. 1998. Human serum amyloid A has cytokine-like properties. Scand. J. Immunol. 47:410-418.

Pezeshki, A., A. V. Capuco, B. De Spiegeleer, L. Peelman, M. Stevens, R. J. Collier, and C. Burvenich. 2010. An integrated view on how the management of the dry period length of lactating cows could affect mammary biology and defence. J. Anim. Physiol. Anim. Nutr. (Berl.) 94:e7-e30.

Ponchon, B., P. Lacasse, N. Silanikove, S. Ollier, and X. Zhao. 2014. Effects of intramammary infusions of casein hydrolysate, ethylene glycol-bis( $\beta$-aminoethyl ether)-N,N,N',N'-tetraacetic acid, and lactose at drying-off on mammary gland involution. J. Dairy Sci. 97:779-788.

Rabot, A., F. Sinowatz, B. Berisha, H. H. Meyer, and D. Schams. 2007. Expression and localization of extracellular matrix-degrading proteinases and their inhibitors in the bovine mammary gland during development, function, and involution. J. Dairy Sci. 90:740-748.
Rainard, P. 2005. Tackling mastitis in dairy cows. Nat. Biotechnol. $23: 430-432$

Ribeiro, F. P., C. J. Furlaneto, E. Hatanaka, W. B. Ribeiro, M. G. Souza, M. A. Cassatella, and A. Campa. 2003. mRNA expression and release of interleukin- 8 induced by serum amyloid A in neutrophils and monocytes. Mediators Inflamm. 12:173-178.

Sandri, S., D. Rodriguez, E. Gomes, H. P. Monteiro, M. Russo, and A. Campa. 2008. Is serum amyloid A an endogenous TLR4 agonist? J. Leukoc. Biol. 83:1174-1180.

Saremi, B., M. Mielenz, M. M. Rahman, A. Hosseini, C. Kopp, S. Dänicke, F. Ceciliani, and H. Sauerwein. 2013. Hepatic and extrahepatic expression of serum amyloid A3 during lactation in dairy cows. J. Dairy Sci. 96:6944-6954.

Streuli, C. H. 2003. Cell adhesion in mammary gland biology and neoplasia. J. Mammary Gland Biol. Neoplasia 8:375-381.

Svennersten, K., C. O. Claesson, and L. Nelson. 1990. Effect of local stimulation of one quarter on milk production and milk components. J. Dairy Sci. 73:970-974.

Talhouk, R. S., M. J. Bissell, and Z. Werb. 1992. Coordinated expression of extracellular matrix-degrading proteinases and their inhibitors regulates mammary epithelial function during involution. J. Cell Biol. 118:1271-1282.

Vasudevan, P., M. K. Nair, T. Annamalai, and K. S. Venkitanarayanan. 2003. Phenotypic and genotypic characterization of bovine mastitis isolates of Staphylococcus aureus for biofilm formation. Vet. Microbiol. 92:179-185.

Watanabe, A., Y. Yagi, H. Shiono, Y. Yokomizo, and S. Inumaru. 2008. Effects of intrammamary infusions of interleukin-8 on milk protein composition and induction of acute-phase protein in cows during mammary involution. Can. J. Vet. Res. 72:291-296.

Wedlock, D. N., A. R. McCarthy, E. E. Doolin, S. J. Lacy-Hulbert, M. W. Woolford, and B. M. Buddle. 2004. Effect of recombinant cytokines on leucocytes and physiological changes in bovine mammary glands during early involution. J. Dairy Res. 71:154-161.

Wilde, C. J., C. H. Knight, and D. J. Flint. 1999. Control of milk secretion and apoptosis during mammary involution. J. Mammary Gland Biol. Neoplasia 4:129-136.

Xia, H., H. Liu, G. Zhang, and Y. Zheng. 2009. Phenotype and function of monocyte-derived dendritic cells from Chinese rhesus macaques. Cell. Mol. Immunol. 6:159-165.

Yu, T. C., S. E. Chen, T. H. Ho, H. C. Peh, W. B. Liu, A. Tiantong, H. Nagahata, and C. J. Chang. 2012. Involvement of TNF- $\alpha$ and MAPK pathway in the intramammary MMP-9 release via degranulation of cow neutrophils during acute mammary gland involution. Vet. Immunol. Immunopathol. 147:161-169.

Zhao, C., M. W. Wood, E. E. Galyov, U. E. Höpken, M. Lipp, H. C. Bodmer, D. F. Tough, and R. W. Carter. 2006. Salmonella typhimurium infection triggers dendritic cells and macrophages to adopt distinct migration patterns in vivo. Eur. J. Immunol. 36:2939-2950. 